\title{
Política para uma educação bilíngue e inclusiva a alunos surdos no município de São Paulo
}

\author{
Cristina Broglia Feitosa de Lacerda' \\ Neiva de Aquino Albres \\ Silvana Lucena dos Santos Drago"
}

\section{Resumo}

O objetivo deste artigo é analisar a atual política para educação de alunos com surdez no município de São Paulo, já que tal política tem impacto na indução de ações no sentido de criar ou não melhores condições para a aprendizagem desse alunado. A educação de surdos é tema polêmico e resultados satisfatórios nem sempre são alcançados. A língua de sinais é a língua de constituição de sujeitos surdos e, quando assumida nos espaços educacionais, favorece um melhor desempenho desses sujeitos. Propostas de escolas de surdos e de educação inclusiva emergem e debatem o direito linguístico da pessoa surda, a abordagem metodológica e a atuação de profissionais bilíngues, além de demandarem políticas governamentais para sua implementação. No Brasil, a Lei n ${ }^{\circ} 10.436$, de 2002, e o Decreto $\mathrm{n}^{\circ}$ 5.626, de 2005, tratam da língua brasileira de sinais (Libras) e da educação de surdos, indicando a necessidade de formação de futuros profissionais (professor bilíngue, instrutor surdo e intérprete de Libras) cientes da condição linguística diferenciada dos alunos surdos. Nessa perspectiva, destaca-se o caso do município de São Paulo, que conta com surdos inseridos em dois contextos educacionais distintos: escolas municipais de educação bilíngue (para alunos surdos) e escolas regulares (que recebem alunos ouvintes e surdos) regulamentadas pelo Decreto no 52.785, de 2011, que cria escolas municipais de educação bilíngue para surdos (EMEBS) na rede municipal de ensino, e pela Portaria n 5.707, também de 2011, que regulamenta o referido decreto.

\section{Palavras-chave}

Educação inclusiva - Educação de surdos - Língua de sinais Políticas públicas em educação.

I- Universidade Federal de São Carlos,

São Carlos, SP, Brasil.

Contatos: cristinalacerda@uol.com.br;

neivaaquino@yahoo.com.br

II- Secretaria Municipal de Educação de

São Paulo, São Paulo, SP, Brasil.

Contato: silvanadrago@yahoo.com.br 


\title{
A policy for bilingual education extensive to deaf pupils of the municipality of São Paulo
}

\author{
Cristina Broglia Feitosa de Lacerda' \\ Neiva de Aquino Albres \\ Silvana Lucena dos Santos Drago"
}

\begin{abstract}
The objective of this article is to analyze the current policy for education of deaf pupils of the municipality of São Paulo, considering that such policy has an impact on the induction of actions towards creating better learning conditions for these pupils. The education of deaf pupils is controversial and satisfactory results are not always achieved. Sign language is the constitutive language of deaf people and whenever it is accepted within educational scenarios it tends to favor an improved performance of these pupils. Proposals for schools for deaf pupils and of an inclusive education have emerged and put under debate the linguistic rights of deaf people, the existing methodological approaches and the role of bilingual professionals, and have also demanded government policies for their implementation. In Brazil, the 2002 Act No 10436 and the 2005 Decree No 5626, which deal with the Brazilian Sign Language (Libras) and with the education of deaf people, signal to the need to educate future professionals (bilingual teachers, deaf instructors and Libras interpreters) that are aware of the special linguistic situation of deaf pupils. Under this perspective, the text explores the case of the municipality of São Paulo, which has deaf pupils inserted into distinct educational contexts: municipal schools of bilingual education (for deaf pupils) and regular schools (that accept both hearing and deaf pupils) regulated by the 2011 Decree No 52785 that creates municipal schools of bilingual education for the deaf (EMEBS in the Portuguese acronym) within the municipal school system, and by the 2011 Ordinance No 5707 that regulates the above-mentioned Decree.
\end{abstract}

\section{Keywords}

Inclusive education - Education of deaf pupils - Sign language Public policies in education.

I- Universidade Federal de São Carlos, São

Carlos, SP, Brazil.

Contacts: cristinalacerda@uol.com.br;

neivaaquino@yahoo.com.br

II- Secretaria Municipal de Educação de São

Paulo, São Paulo, SP, Brazil.

Contact: silvanadrago@yahoo.com.br 


\section{Propostas políticas para a educação de surdos}

A educação de surdos é tema polêmico desde seus primórdios. A língua de sinais é sabidamente língua de constituição de sujeitos surdos (MOURA, 2000), e quando é assumida em espaços educacionais, favorece um melhor desempenho dos alunos surdos (LODI; LACERDA, 2009).

Os prós e os contras das propostas de escolas de surdos e da educação inclusiva não se restringem ao direito linguístico, ao contato com pares usuários da mesma língua, à abordagem metodológica ou à atuação de profissionais bilíngues, entre outros, mas ampliam-se para as condições concretas de implementação dessas mesmas propostas nas políticas governamentais. Assim, destaca-se o caso do município de São Paulo, que conta com alunos surdos inseridos em dois contextos educacionais distintos: escolas municipais de educação bilíngue (para alunos surdos) e escolas regulares (que recebem alunos ouvintes e surdos). Nessa perspectiva, é fundamental que nos dois espaços sejam desenvolvidas ações coerentes com os princípios de uma educação bilíngue para surdos em direção a uma educação de qualidade.

A questão do acesso à língua de sinais é premente no atendimento educacional à criança surda. Qualquer ação pedagógica precisa considerar sua condição linguística e oferecer a Libras (língua brasileira de sinais) como forma de acesso. Contudo, isso não é observado em várias experiências escolares em cujas salas de aula atuam profissionais com domínio parcial de Libras (LEBEDEFF, 2010; QUADROS, 2006).

0 número de alunos surdos matriculados em classes de ouvintes nas escolas regulares é crescente (MELETTI; BUENO, 2010), e nelas tais alunos são chamados de surdos incluidos. Infelizmente, na maioria desses casos o aluno surdo é tratado como se ouvinte fosse, devendo acompanhar os conteúdos preparados para ouvintes sem que qualquer condição especial seja propiciada para sua aprendizagem (SILVA; PEREIRA, 2003).
As comunidades surdas no Brasil, aliadas a pesquisadores atentos às necessidades de aquisição e desenvolvimento de linguagem das pessoas surdas, passaram a debater a importância de se ofertar uma educação em uma perspectiva bilíngue para surdos. As duas últimas décadas foram importantes para uma melhor compreensão das necessidades educacionais de alunos surdos e para o avanço de políticas públicas nessa direção. Assim, como resultado de debates, pressões e reivindicações da comunidade surda e acadêmica, emerge uma nova legislação federal - Lei $n^{\circ} 10.436$, de 24 de abril de 2002 (BRASIL, 2002), e Decreto $\mathrm{n}^{\circ}$ 5.626, de 22 de dezembro de 2005 (BRASIL, 2005) -, o que é importante para nortear o atendimento escolar do aluno surdo com atenção a aspectos da abordagem bilíngue.

A Lei $n^{\circ}$ 10.436/02 (BRASIL, 2002) refere-se ao reconhecimento e à legitimidade da Libras em todos os espaços públicos, e também à obrigatoriedade de seu ensino como parte integrante das diretrizes curriculares nos cursos de formação de educação especial, fonoaudiologia e magistério, em nível médio e superior. Já o Decreto no 5.626/05 (BRASIL, 2005) trata, entre outras providências, sobre educação de surdos, modos de atendimento nos diferentes níveis de ensino e modos de prover acessibilidade linguística a eles, além da inclusão da Libras como disciplina curricular nos cursos de magistério, educação especial, fonoaudiologia, pedagogia e demais licenciaturas. Amplia-se, assim, a difusão da Libras e sinaliza-se o interesse pela formação de futuros profissionais cientes da condição linguística diferenciada dos alunos surdos. 0 mesmo decreto também dispõe sobre a formação do professor bilíngue e do instrutor surdo de Libras; a formação do tradutor e intérprete de Libras/língua portuguesa; e o direito dos surdos de ter acesso às informações em Libras e à educação bilíngue.

Políticas de educação especial voltadas ao alunado surdo são importantes porque podem induzir ações no sentido de criar melhores condições de aprendizagem para tal alunado, 
já que suas dificuldades educacionais não são inerentes à condição de surdez e o atendimento educacional bilíngue pode favorecer seu aproveitamento escolar (SVARTHOLM, 2008). Nessa perspectiva, o objetivo do presente artigo é realizar uma análise da política de educação de alunos com surdez no município de São Paulo na atualidade.

\section{Aspectos teórico-metodológicos que embasam este estudo}

$\mathrm{Na}$ escola, o aluno surdo alcança um nível de desempenho satisfatório quando há preocupação com o resgate de sua história, compreensão de sua singularidade linguística e uma educação que valorize suas capacidades e potencialidades, além de uma atenção às formas de organização social das comunidades surdas e à importância da Libras no processo educativo e nas demais instâncias cotidianas. Acrescenta-se a isso a relevância da disposição de recursos - sejam eles humanos, materiais, metodológicos ou outros - importantes para um ensino de qualidade no espaço escolar (LODI; LACERDA, 2009).

0 processo de aquisição da linguagem ocorre de forma gradual, já que se constitui como base simbólica essencial para o desenvolvimento humano, e a educação depende fundamentalmente da linguagem para promover a construção de conhecimentos. Desse modo, linguagem e língua são pilares centrais em qualquer contexto educacional. Vygotsky (1998) aponta para a centralidade do uso de signos e instrumentos na constituição do sujeito, pois estes são mediadores - auxiliares - da atividade mental superior humana. Os signos são instrumentos psicológicos que colaboram e configuram as construções mentais, já que são orientados internamente. 0 processo contínuo de construção das significações nasce das experiências externas que se internalizam e constituem o indivíduo. É nas ações, nas interações sociais e na linguagem que o homem mergulha nessa rede de significações e representações simbólicas, transformando-se e se desenvolvendo ao longo de toda sua vida. E tal processo complexo não pode ocorrer sem uma língua estruturada e compartilhada socialmente que favoreça as mediações e as construções de sentido.

Bakhtin (1986), estudioso das questões da língua e da linguagem, também se apoia em uma perspectiva histórico-cultural, afirmando que é a partir do meio ideológico e social que se forma a consciência individual. Assim, a palavra é fundamental na constituição dessa consciência, exercendo a função de signo. Para o autor, o dialogismo ocupa lugar central, pois os processos que envolvem a linguagem são responsáveis pela complexidade da vida humana. De acordo com ele, toda enunciação é um diálogo e, portanto, o enunciado não é algo isolado, mas sim um elo de uma cadeia infınita, num processo de comunicação ininterrupto.

A Libras é uma língua visual-espacial utilizada naturalmente em comunidades surdas brasileiras, permitindo expressar sentimentos, ideias, ações e qualquer conceito e/ou significado para estabelecer interações entre sujeitos. A língua de sinais possui todas as características linguísticas de qualquer língua humana natural. Como as demais línguas orais, ela não é universal; ao longo do território brasileiro, apresenta variações que advêm das características regionais, sociais e culturais de cada lugar. É uma língua autônoma, dotada de gramática específica estruturada nos diversos níveis linguísticos (GESSER, 2009). A importância da Libras para o desenvolvimento dos alunos surdos é enorme, já que "todas as esferas da atividade humana, por mais variadas que sejam, estão sempre relacionadas com a utilização da língua"; tal utilização, por sua vez, "efetua-se em forma de enunciados (orais e escritos), concretos e únicos, que emanam dos integrantes duma ou doutra esfera da atividade humana" (BAKHTIN, 1997, p. 279), conferindo à enunciação/linguagem/língua papel fundamental na apropriação e na construção de conceitos.

Assim, os textos legais constituem importante campo de pesquisa, já que neles estão 
materializadas ideias e propostas de implementação de práticas que interferem diretamente na vida das pessoas, de modo que a melhor compreensão de tais textos pode colaborar, em nosso caso específico, para o melhor atendimento de sujeitos surdos.

As pesquisas no campo das políticas públicas têm-se mostrado fundamentais aos estudos educacionais, já que os documentos oficiais são instrumentos para a concretização dos direitos dos cidadãos. Além disso, entende-se que esses documentos representam a política, apesar de não a serem de fato, e devem ser vistos como parte de um processo contínuo "cujo locus de poder está constantemente mudando" (SHIROMA; CAMPOS; GARCIA, 2005, p. 433).

Compreendemos, pois, que a análise de uma fonte legal é apenas um instrumento para interpretação, apesar de ser uma peça fundamental. Para Cury (2002, p. 246), o contorno legal indica direitos, deveres, proibições, possibilidades e limites de atuação:

Tal conjunto possui impacto no cotidiano das pessoas, mesmo que nem sempre estejam conscientes de suas implicações e consequências.

Assim, para este estudo foram considerados documentos sobre o atendimento da educação especial no município de São Paulo visando analisar a proposta de educação para surdos explicitada nos seguintes textos: Decreto no 52.785, de 10 de novembro de 2011 (cria escolas municipais de educação bilíngue para surdos - EMEBS na rede municipal de ensino) e Portaria $\mathrm{n}^{\circ}$ 5.707, de 12 de dezembro de 2011 (regulamenta o Decreto no 52.785, que criou as escolas de educação bilíngue para surdos - EMEBS na rede municipal de ensino e dá outras providências). Também foram consideradas entrevistas com gestores da diretoria de orientação técnica da área de educação especial (DOT-EE) e da equipe assessora, todos ligados à Secretaria Municipal de Educação de São Paulo (SME/SP).

\section{Análise da política proposta pela rede municipal de educação de São Paulo}

A oferta dos atendimentos da educação especial na rede municipal de educação já era prática desenvolvida anteriormente à publicação dos documentos em análise, com escolas municipais especiais para alunos surdos e salas de apoio pedagógico especializado para os alunos surdos matriculados nas demais unidades educacionais.

Com o Decreto no 52.785/11, a educação especial transformou as escolas especiais em bilíngues e definiu a escolha de algumas escolas regulares como polos de atendimento inclusivos e bilíngues para surdos. 0 foco central dos documentos analisados é marcar a Libras como língua de acesso aos conhecimentos pelos alunos surdos e criar condições a fim de que ela circule nas escolas. Para tanto, indica-se a necessidade de formação de coordenadores, professores bilíngues, professores do ensino regular, demais professores, instrutores surdos e intérpretes de Libras.

A gestora da DOT-EE, em entrevista, indica que a construção de uma educação bilíngue precede tal documento, datado de 2011.

Em 2005 a SME realizou reunião com os gestores das escolas municipais de educação especial (EMEES) a fim de identificar as dificuldades e levantar propostas para melhorar o funcionamento dessas unidades, visando oferecer suporte pedagógico para a escola, para o professor e para os alunos. Foram apontadas como prioridade a organização de diretrizes, definição do currículo para as EMEEs e a formação especifica para atender as necessidades das equipes que atuam nessas unidades. (Gestora da DOT-EE, entrevista, 2012)

Embora houvesse a oferta de atendimentos da educação especial e das escolas especiais de surdos, não havia garantia de respeito ao direito linguístico do aluno surdo. Durante várias 
décadas imperou o modelo oralista de educação de surdos e muitos profissionais foram contratados e formados nesse contexto. Há uma mudança histórica e social de paradigma (SKLIAR, 1999) - considerando a surdez como uma característica socioantropológica e a Libras como língua de direito - que é defendida nas esferas políticas e sociais (associações de surdos, acadêmica, entre outras), mas não necessariamente assimilada pelas práticas escolares. Diante desse quadro, a SME/SP trabalhou na perspectiva de formação continuada do corpo docente:

Em 2005 foram planejadas ações de formação para os professores e os gestores e para aquisição de materiais e equipamentos para as EMEEs, bem como procedimentos para a contratação de intérpretes, organização de cursos de Libras para educadores e funcionários e a realização do Festival Esportivo e Cultural de Alunos Surdos da Rede Municipal de Ensino. (Gestora da DOT-EE, entrevista, 2012)

Desse modo, os documentos analisados indicam um posicionamento político em relação à educação de surdos, mantendo a estrutura de escolas de surdos, assumindo a participação destes também nas escolas regulares e prevendo, contudo, uma estrutura mais atenta à condição bilíngue de tais sujeitos. Em ambos os casos garantem-se ações mediadas pela Libras. Assim, mantém-se um funcionamento histórico defendido por profissionais que atuam nessas unidades, usuários, familiares e comunidade surda e, ao mesmo tempo, oferta-se uma modalidade de educação bilíngue inclusiva para responder à demanda de alunos surdos fora do alcance dessas unidades.

Em 2005 foi publicado o Decreto Federal $\mathrm{n}^{0} 5.626$ (BRASIL, 2005), no qual foram indicados novos profissionais a serem integrados nas escolas responsáveis pelo atendimento de alunos surdos. Tais profissionais foram definidos como necessários para uma educação bilíngue; são eles: professor bilíngue, professor e/ou instrutor de Libras e intérprete de Libras. Acompanhando pressupostos semelhantes, o Decreto no 52.785 (SÃO PAULO, 2011a) define, entre os profissionais necessários para execução de educação bilíngue para surdos e de serviços da educação especial nas escolas inclusivas bilíngues (escolas-polo), os seguintes:

Art. $6^{0}$ - São considerados profissionais especializados no atendimento aos alunos surdos, nos termos da presente Portaria:

I - Professor de Educação Infantil;

II - Professor de Educação Infantil e Ensino

Fundamental I;

III - Professor de Ensino Fundamental II e Médio;

IV - Instrutor de LIBRAS;

V - Intérprete de LIBRAS;

VI - Guia-intérprete.

(SÃO PAULO, 2011b)

Os profissionais indicados nos pontos I, II e III devem ser professores bilíngues (com domínio em português e Libras) concursados da rede municipal de educação; já os profissionais indicados nos pontos IV, V e VI seriam profissionais bilíngues a serem contratados emergencialmente, visto não estarem disponíveis nos quadros municipais devido à novidade da proposta e à ausência desses cargos na SME/SP.

Antes da definição dos profissionais, a SME/SP desenvolveu ações no campo documental das escolas e do currículo propriamente dito, construindo o currículo de português para surdos e de Libras para surdos em todo o ensino fundamental, como comenta a gestora:

Em 2008, o objetivo era elaborar Orientações Curriculares e Proposição de Expectativas de Aprendizagem de Língua Portuguesa para alunos surdos da Educação Infantil ao $9^{\circ}$ ano do Ensino Fundamental, o que contou com a participação de um grupo representativo das EMEEs que realizavam a articulação entre o grupo e os professores das escolas, de forma que todos par- 
ticipassem do processo. Nesse mesmo ano também foram elaboradas as Orientações Curriculares e Proposição de Expectativas de Aprendizagem da Lingua Brasileira de Sinais - Libras para os alunos surdos desde a Educação Infantil ao $9^{\circ}$ ano do Ensino Fundamental.

Na elaboração desse material, participaram representantes de todas as EMEEs, profissionais dos Centros de Formação e Acompanhamento à Inclusão - CEFAI e das Diretorias de Ensino, bem como professores surdos, experientes no ensino da Libras. (Gestora da DOT-EE, entrevista, 2012)

Assim, destaca-se a proposta de atuação nas escolas de novos profissionais responsáveis pelo atendimento de alunos surdos: um professor especialista no ensino de português para surdos e um professor de Libras. 0 discurso da gestora dá destaque à produção coletiva tanto discutida em gestão democrática para a efetivação de qualquer proposta, visto que os profissionais se sentem produtores e envolvidos em um novo projeto da rede de ensino.

Trabalharemos aqui, então, de forma mais detalhada sobre o perfil dos profissionais previstos nos documentos analisados, por considerarmos este um aspecto fundamental da proposta.

\section{a) Professor bilíngue}

0 professor bilíngue é um professor com formação em curso superior de pedagogia ou em licenciatura específica que atua no processo de ensino-aprendizagem em escolas bilíngues. No país, muitas escolas têm-se organizado como escolas bilingues, principalmente nos pares linguísticos inglês/português e francês/português (MEGALE, 2005). No âmbito da educação de surdos, a educação bilíngue Libras/português ganha força com a regulamentação da Lei de Libras, por meio do Decreto no 5.626/05 (BRASIL, 2005), como já argumentado anteriormente.

Em programas de educação bilíngue para surdos, há necessidade de diferentes profissio- nais (professores bilíngues, instrutores surdos de Libras, intérpretes de Libras) nos quadros da rede de educação, como indicam Lodi e Lacerda (2009). Todavia, o conceito de professor bilíngue é ainda fluido, sem contornos bem definidos. Fernandes (2012, p. 105) indica que o professor bilíngue é o "professor com fluência em Libras que desenvolverá o ensino do português escrito com base em metodologias de ensino de segunda língua”.

Destaca-se, ainda, que a legislação nacional prevê a formação desse professor em curso de pedagogia bilíngue:

Capítulo III - Art. 50 A formação de docentes para o ensino de Libras na educação infantil e nos anos iniciais do ensino fundamental deve ser realizada em curso de Pedagogia ou curso normal superior, em que Libras e Língua Portuguesa escrita tenham constituido línguas de instrução, viabilizando a formação bilíngue. (BRASIL, 2005)

Consideramos que esse artigo do decreto prevê a formação do professor em curso bilíngue, mas não menciona detalhes da formação para a execução de uma educação bilíngue, ou seja, não faz referência a aspectos da formação pedagógica para a prática de ensino no contexto da educação bilíngue. 0 fato de a formação se dar em duas línguas distintas de instrução não garante a apropriação de saberes docentes para a execução de uma educação bilíngue. Ainda em relação à formação do profissional, o documento indica:

III - professor ouvinte bilíngue: Libras Língua Portuguesa, com pós-graduação ou formação superior e com certificado obtido por meio de exame de proficiência em Libras, promovido pelo Ministério da Educação. (BRASIL, 2005)

Dessa forma, para a promoção de uma educação bilíngue, exige-se o conhecimento linguístico, mas não necessariamente $o$ 
conhecimento pedagógico. No que tange à ação pedagógica em educação bilíngue, o decreto prevê a criação de cursos de pedagogia bilíngue:

I - para formação de professores surdos e ouvintes, para a educação infantil e anos iniciais do ensino fundamental, que viabilize a educação bilíngue: Libras Língua Portuguesa como segunda língua. (BRASIL, 2005)

Atualmente, esse tipo de curso de formação de professores em pedagogia bilíngue é incipiente no Brasil, havendo apenas um curso oferecido no Instituto Nacional de Educação de Surdos, no Rio de Janeiro (INES, 2012). É importante salientar que a intenção desse curso é a formação prioritária de professores surdos em curso de pedagogia, conforme indicado no Decreto $n^{0}$ 5.626/05 (BRASIL, 2005).

0 ensino bilíngue para surdos, em que a Libras é a língua de instrução (L1) e o português é tratado como segunda língua (L2), possui peculiaridades que dependem da localização das diferentes modalidades de ensino oferecidas aos estudantes surdos ao longo de sua trajetória escolar. (FRANCO, 2009, p. 19)

Assim, há uma única experiência nesse sentido e ainda em processo de ajustes e avaliação, formando poucos alunos a cada ano no Estado do Rio de Janeiro. Torna-se pouco provável, pois, que as secretarias de educação dos diversos Estados e municípios brasileiros possam ter tal formação como requisito para a contratação do profissional. Desse modo, constata-se que, no âmbito da SME/SP, a exigência de formação de tal profissional se dá pelo seguinte texto:

$\S 1^{\circ}$ - Os professores referidos nos incisos I a III, integrantes da Carreira do Magistério Municipal, serão denominados Professores Bilíngues se comprovada, além da habilitação na área de atuação, aquela específica na área de surdez, em nível de graduação ou especialização, na forma da pertinente legislação em vigor. (SÃO PAUL0, 2011b)

Exige-se inicialmente, portanto, um conhecimento acadêmico na área da surdez e uma formação pedagógica para a aplicação de uma educação bilíngue. Além disso, no artigo 13 da mesma portaria, registra-se a importância do compromisso com a formação continuada, sendo nas EMEBS que:

I - Os professores da Educação Infantil deverão participar da formação sobre vivências específicas que contemplem aspectos da aquisição de linguagem e desenvolvimento da criança surda (SÃO PAULO, 2011b)

A partir desse ponto explicitado no documento, entende-se que dos professores bilíngues, para atuação na educação infantil, serão requeridos conhecimentos que, outrora não mencionados e aqui mais bem detalhados, remetem à especificidade da aquisição da linguagem, aspecto central no desenvolvimento dos alunos surdos.

II - Os professores de Ciclo I deverão participar da formação específica sobre metodologia de ensino de Língua Portuguesa como segunda língua para surdos e demais componentes curriculares que serão promovidos por SME/DOT-EE/CEFAI.

IV - Os professores do Ciclo II que vierem a ministrar aulas do componente curricular Língua Portuguesa deverão participar de cursos de formação continuada em metodologia no ensino de segunda língua para surdos, promovidos por SME/DOT-EE/ CEFAI. (SÃO PAULO, 2011b)

Por essa legislação, professores bilíngues, tanto os com formação em pedagogia que 
trabalham com o letramento nas séries iniciais quanto aqueles com formação em Letras/português (especialistas) que ministram a disciplina de português, ficam obrigados a passar por formação continuada para aperfeiçoar conhecimentos sobre metodologia do ensino de segunda língua para surdos. Cabe destaque aqui que o ensino de português para surdos é um entrave recorrentemente discutido na literatura (LODI, 2004; PEREIRA, 2005; FERNANDES, 2006) e que merece ser enfrentado prevendo-se formação continuada que atente para as dificuldades e singularidades do processo e favoreça aos professores o desenvolvimento de ações pedagógicas compatíveis com o objetivo proposto, qual seja: ensinar português na modalidade escrita com base nos conhecimentos em língua de sinais.

V - Os professores do Ciclo II que vierem a ministrar aulas dos demais componentes curriculares deverão participar de cursos de formação continuada em metodologias de ensino específica para surdos, promovidos por SME/DOT-EE/ CEFAI. (SÃO PAULO, 2011b)

Aos professores bilíngues que trabalhem com outras áreas do conhecimento além das que envolvem o ensino de línguas, também é indicada, no artigo 13 da referida portaria, a necessidade de formação para maior conhecimento sobre metodologias de ensino específicas para surdos, tal como a execução de uma pedagogia visual, e sobre aspectos da Libras que favoreçam o ensino das diferentes disciplinas, entre outras questões. É recomendado que os professores do $1^{\circ}$ ciclo participem dos dois tipos de formação, tanto para o ensino de língua portuguesa quanto para o ensino dos demais componentes curriculares, uma vez que são responsáveis pela formação dos alunos nas diversas áreas do conhecimento nos anos iniciais do ensino fundamental. Além das questões metodológicas e do fazer docente no processo de ensino-aprendizagem, na portaria também está prevista a formação continuada em Libras.
$\S 1^{\circ}$ - Os Professores Bilíngues deverão participar, ainda, das ações de formação continuada em LIBRAS oferecida por DOT/ SME, em parceria com o CEFAI da DRE. (SÃO PAULO, 2011b)

Os pontos destacados revelam a compreensão dos gestores dessa Secretaria de que o perfil do professor bilíngue vai além de seu domínio linguístico em português, de seu domínio linguístico em Libras ou de sua formação como professor. 0 documento indica a consideração de que também o conhecimento de processos de ensino-aprendizagem, procedimentos metodológicos e curriculares que levem em conta a característica sociocultural e linguística do sujeito surdo são indispensáveis. A portaria considera a incorporação de profissionais já presentes na rede municipal de educação, mas indica a mesma Secretaria com função de formadora de especificidades de seu corpo docente para o atendimento adequado da clientela surda.

Esse caminho revela o interesse pela execução de um programa de educação bilíngue com ações previstas para curto, médio e longo prazo. No curto prazo, são indicados professores da rede fluentes em português e Libras, mas são previstas formações continuadas para ampliar tanto o domínio em Libras, quanto o conhecimento de metodologias de ensino adequadas aos sujeitos surdos. Assim, não se trata de simples deliberação de exigência de formação prévia, o que seria irreal no cenário de formação de professores atual, sem a oferta de condições para a construção e a consolidação do programa de educação bilíngue.

Entre os mecanismos criados, está a formação continuada e em serviço já muito trabalhada com os professores da rede municipal de ensino de maneira geral. A própria rede municipal assume o papel de formar continuamente seus quadros, e com o professor bilíngue não poderia ser diferente.

A oferta de formação continuada pode ser realizada tanto pela própria diretoria de orientação técnica da educação especial, que 
contrata profissionais afınados com suas diretrizes, quanto pela contratação de outras instituições de ensino para execução de tal tarefa, como aponta a gestora da DOT-EE em entrevista:

Como previsto, o Programa Inclui está estruturado em sete projetos, sendo que um deles é o Projeto Reestruturar. Dentre as metas do projeto estão:

1. Elaboração de proposta para a organização de escolas bilíngues, currículo e avaliação na perspectiva da educação bilíngue.

2. Organização da formação das equipes que atuarão nessas escolas.

3. Elaboração de um documento orientador da Politica de Atendimento para Alunos Surdos na Rede Municipal de Ensino.

Para atender à meta 2, dentre as atividades, desenvolvemos curso de pós-graduação lato sensu em parceria com universidades públicas e privadas e formação de grupos de trabalhos (GTs) executados na própria Secretaria por meio de assessoria de pesquisadores externos. (Gestora da DOTEE, entrevista, 2012)

Dessa forma, a Secretaria faz uso de seu pessoal e proporciona a formação continuada em nível de pós-graduação lato sensu ou de capacitação. Sabemos dos entraves para a oferta de formação continuada para professores em serviço: horários compatíveis, locais acessíveis, demanda de tempo para estudo e aprofundamento. A formação continuada é bastante necessária, mas nem por isso é simples de ser implementada (TEIXEIRA, 2002).

Os professores bilíngues podem também assumir a disciplina de ensino de Libras. Tal disciplina tem como objetivo ampliar os conhecimentos e a reflexão sobre a língua brasileira de sinais considerando seu uso e seus aspectos gramaticais. Nesse sentido, há uma distinção entre o professor de Libras, responsável pela referida disciplina, e o instrutor de Libras. Esperase que os professores bilíngues da rede municipal tenham como formação:
Art. $8^{\circ}$ - Os professores que vierem a ministrar aulas do componente curricular LIBRAS deverão apresentar formação, observada a seguinte ordem:

I - graduação em LETRAS/LIBRAS;

II - pós-graduação em LIBRAS;

III - certificação de proficiência em LIBRAS;

IV - experiência comprovada de docência em LIBRAS.

(SÃO PAULO, 2011b)

Assim, para ser responsável por essa disciplina nas unidades escolares, é exigida formação em nível de graduação ou pós-graduação lato sensu ou, na falta de tal formação, experiência no ensino de Libras.

\section{b) Instrutor de Libras}

A formação de docentes para o ensino de Libras nas séries iniciais e finais do ensino fundamental, no ensino médio e na educação superior deveria ser realizada em nível superior, em curso de graduação em pedagogia bilíngue ou em licenciatura plena em Letras/ Libras, como prevê o Decreto no 5.626/05 (BRASIL, 2005). Contudo, sabemos que o curso Letras/Libras, ainda bastante recente no país, foi oferecido na modalidade à distância em quinze polos em 2008 e em vinte polos em 2010, com turmas de cinquenta alunos em cada um dos polos espalhados pelo Brasil. Em São Paulo, formaram-se quarenta pessoas em 2010, o que certamente constitui um número insuficiente para atender às demandas de ensino das redes municipais, estaduais e de ensino superior que se estão consolidando na perspectiva de uma educação bilíngue e considerando alunos surdos. Alguns novos cursos presenciais estão sendo organizados e oferecidos, mas o conjunto de vagas ainda é tímido perto da necessidade real da área.

Assim, a Portaria $n^{0} 5.707$ (SÃO PAULO, 2011b), sensível a essa realidade, define o profissional a ser contratado pela SME/SP como 
preferencialmente surdo com certificação mínima em nível médio e certificado de proficiência no uso e no ensino de Libras.

0 certificado de proficiência mencionado é o Prolibras, exame nacional promovido pelo Ministério da Educação e aplicado por instituições de ensino superior (IES). 0 objetivo do exame é viabilizar a certificação de proficiência em língua brasileira de sinais para sua tradução, sua interpretação e seu ensino. 0 Prolibras certifica: a) pessoas, surdas ou ouvintes, fluentes em Libras, aprovadas no exame de proficiência em Libras, interessadas em ser professores ou instrutores de Libras; b) pessoas, ouvintes ou surdas, fluentes em Libras, aprovadas no exame de proficiência em tradução e interpretação de Libras interessadas em exercer essa função.

A SME/SP indica que a função de instrutor de Libras será preferencialmente destinada aos profissionais surdos, visto que eles são modelo linguístico e de identidade surda, fomentam o uso da Libras em todos os espaços da escola e, por constituírem-se como surdos e por suas trajetórias de vidas, têm condições experienciais e linguísticas de contribuir de forma ímpar para a construção de uma didática bilíngue. Além disso, assim a Secretaria favorece a inclusão profissional dos surdos no campo da educação.

[...] a construção da subjetividade do ser surdo depende, fundamentalmente, da relação que eles estabelecem tanto com seus pares quanto com ouvintes e, nesse sentido, a presença de professores surdos na educação ganha relevância para a construção de uma percepção positiva da surdez pelos alunos. (LODI, 2005, p. 419)

Nessa perspectiva, o professor ou instrutor surdo é importante como um outro que contribuirá para a constituição das crianças surdas em relação com um todo social diverso, não mais pautado apenas na percepção de um mundo exclusivamente ouvinte, mas em coexistência de duas formas de vivenciar o mundo.
0 instrutor surdo será responsável por realizar atividades de formação em Libras para a comunidade escolar, incluindo aí os pais e familiares dos alunos surdos e ouvintes das turmas em que há alunos surdos incluídos (art. 11, $\S 2^{\circ}$, da Portaria $n^{\circ}$ 5.707). Assim, os instrutores, preferencialmente surdos, têm tanto a tarefa de ensinar Libras para toda a comunidade escolar, quanto a de acompanhar e trabalhar colaborativamente com os professores bilíngues que assumirão o componente curricular Libras em todos os anos do ensino fundamental ( $2^{\circ}$ ciclo).

$\S 4^{\circ}$ - As aulas de LIBRAS serão ministradas pelo Professor Bilíngue regente acompanhado pelo Instrutor de LIBRAS, preferencialmente surdo. (SÃO PAULO, 2011b)

A estratégia da SME/SP, pela condição de ter em sua maioria professores bilíngues ouvintes, é de que tais professores tivessem o apoio do instrutor surdo, levando em consideração as questões já pontuadas relativas a modelo linguístico e percepção positiva da surdez.

Esses profissionais não figuravam no quadro funcional do município e precisam ser criados cargos e funções, indicando-se ações a serem postas em prática a médio e longo prazo. A diferença entre professor e instrutor de Libras estará na titulação: por já ser graduado ou ter apenas o ensino médio, respectivamente.

$\S 1^{\circ}$ - do art. 11 - Usa a Libras para se comunicar em todos os espaços e momentos da escola, visando com essa ação ser modelo linguístico para as crianças surdas nas unidades educacionais participantes da proposta de educação bilíngue, nas EMEBS e nas Unidades-Polo indicadas pela SME. (SÃO PAULO, 2011b)

As mudanças propostas nos documentos apontam alteração na estrutura e na organização da educação especial, em um movimento de maior especialização das escolas exclusivas para surdos, de um lado, e de descentralização 
da educação de surdos de outro, quando organiza sua inserção bilíngue também em escolas regulares.

\section{c) Intérprete de Libras}

Interessa destacar a importância do intérprete de língua de sinais nos vários contextos educacionais para desenvolver a mediação entre usuários de Libras e de português em escolas inclusivas. 0 Decreto $n^{0}$ 5.626/05 (BRASIL, 2005) prevê, em seu capítulo V, artigo 17, a necessidade de formação do tradutor e intérprete de Libras/língua portuguesa (TILS) por meio de curso superior de tradução e interpretação, com habilitação em Libras/ língua portuguesa. Atualmente, esse curso específico é oferecido por poucas instituições de ensino superior, e a realidade vivenciada é a da formação promovida principalmente em práticas sociais diversas (espaços religiosos, associações de surdos, entre outros) e no contexto escolar.

Dando sequência, o artigo 18 do referido Decreto determina que, nos dez anos seguintes à sua publicação, será aceita a formação do TILS em nível médio realizada por meio de cursos de educação profissional, cursos de extensão universitária e cursos de formação continuada promovidos por instituições de ensino superior e instituições credenciadas por secretarias de educação. Dispõe o documento, ainda, que tal formação pode ser realizada por organizações da sociedade civil representativas da comunidade surda, com a condição de que o certificado seja convalidado por uma das instituições referidas anteriormente. Essa última instância de formação visa atender à demanda de serviços que decorre das mudanças no atendimento dos surdos em todos os setores públicos (educacional, saúde, judicial, entre outros) e que não pode aguardar a formação em larga escala de profissionais TILS em nível superior.

Ainda em relação à preocupação com a demanda e a capacitação profissional na área nos dez anos seguintes à sua publicação, o artigo
19 indica que, em não havendo pessoas com a titulação exigida para o exercício da profissão nas instituições de ensino, pode-se recorrer a profissionais com o seguinte perfil:

I - profissional ouvinte, de nível superior, com competência e fluência em Libras para realizar a interpretação das duas línguas, de maneira simultânea e consecutiva, e com aprovação em exame de proficiência, promovido pelo Ministério da Educação, para atuação em instituições de ensino médio e de educação superior;

II - profissional ouvinte, de nível médio, com competência e fluência em Libras para realizar a interpretação das duas línguas, de maneira simultânea e consecutiva, e com aprovação em exame de proficiência, promovido pelo Ministério da Educação, para atuação no ensino fundamental;

III - profissional surdo, com competência para realizar a interpretação de línguas de sinais de outros países para a Libras, para atuação em cursos e eventos. (BRASIL, 2005)

A legislação vigente impacta diretamente o TILS que atua no campo educacional. 0 intérprete é uma figura importante para que os alunos surdos usuários da Libras tenham acesso, nas escolas regulares onde a língua de instrução é o português, não apenas aos conteúdos escolares, mas também a oportunidades de inserção/interação social no espaço escolar. Sua função é viabilizar a comunicação entre surdos e ouvintes, atuando na fronteira entre os sentidos da língua oral (português) e da língua de sinais num processo ativo, dinâmico e dialético. Seu trabalho visa a uma contribuição significativa na melhoria do atendimento escolar, configurando-se como espaço de respeito para com o surdo em sua condição linguística e sociocultural, e propiciando o desenvolvimento e a aquisição de novos conhecimentos de maneira adequada (LACERDA, 2000a, 2000b, 2002).

No entanto, a presença do intérprete em sala de aula e o uso da língua de sinais não 
garantem que todas as necessidades educacionais dos surdos sejam atendidas, sendo também importante a disposição de recursos humanos, materiais e metodológicos adequados para que 0 aprendizado realmente se desenvolva. Portanto, a formação para o intérprete educacional

vai além do conhecimento das línguas, que deve ser uma formação plural e interdisciplinar, visando seu trânsito na polissemia das línguas, nas esferas de significação e nas possibilidades de atuação frente a difícil tarefa da tradução/interpretação. (LACERDA, 2007, p. 9)

No âmbito da legislação em análise neste estudo, a SME/SP, no artigo $6^{\circ}$ do documento, aponta o seguinte requisito para credenciamento:

$\S 5^{\circ}$ - 0 Intérprete de LIBRAS, citado no inciso $\mathrm{V}$ deste artigo, será profissional contratado pela SME com certificação mínima em Ensino Médio, e certificação em proficiência na tradução e interpretação da LIBRAS / Língua Portuguesa / LIBRAS. (SÃO PAUL0, 2011b)

Além disso, indica as escolas do ensino regular como espaço de atuação para o intérprete educacional:

Art. $7^{\circ}$ - Constituem-se área de atuação dos profissionais de que trata o artigo anterior: V - Intérprete de LIBRAS - nas escolas de ensino regular que tenham alunos surdos matriculados. (SÃO PAULO, 2011b)

Vê-se que o intérprete educacional trabalha ativamente no processo de ensino-aprendizagem, não só interpretando conteúdos, mas também se envolvendo nos modos de tornar tais conteúdos acessíveis para o aluno a partir de conversas e trocas de informações (LACERDA, 2009). Como qualquer outro profissional que trabalha no espaço escolar, suas opiniões são essenciais em todos os processos envolvidos, pois ele é um forte colaborador para a construção de uma prática pedagógica que seja adequada ao aluno surdo dentro do contexto de uma proposta educacional inclusiva bilingue.

No Brasil, a atuação do intérprete de língua de sinais no cenário escolar é recente e traz ainda indagações sobre sua formação, suas práticas e a realidade que vivencia na escola. São tais inquietações que justificaram a elaboração da pesquisa ora apresentada e das análises que se seguem.

Dessa forma, o sentido da política como ações para a promoção de uma equidade aos bens sociais pode ser interpretado no âmbito da educação de surdos a partir do que diz Skliar (1999, p. 7):

Discutir a educação bilíngue numa dimensão política assume um duplo valor: o "político" como construção histórica, cultural e social, e o "político" entendido como as relações de poder e conhecimento que atravessam e delimitam a proposta e o processo educacional.

0 movimento histórico de construção de uma educação bilíngue para surdos surge da necessidade de uma comunidade reconhecida no Brasil como minoria linguística e tem seu caminho construído em documentos com previsão de criação de cargos.

Paralelamente às ações que vêm sendo implementadas, temos o objetivo de que ao final de 2012 os GTs irão produzir documento orientador para o funcionamento das escolas bilíngues, apontando propostas para o aperfeiçoamento do projeto, e também se pretende organizar recursos e estratégias didáticas para o ensino bilíngue. Além disso, estamos organizando documentos para consulta quanto à possibilidade da criação de cargos de professor de Libras, de intérprete e guia intérprete. (Gestora da DOT-EE, entrevista, 2012) 
Para finalizar, cabe fazer um paralelo com a educação de surdos no cenário nacional. Em 1999, a Federação Nacional de Educação e Integração de Surdos (FENEIS) produziu a carta aberta $A$ educação que nós surdos queremos (FENEIS, 1999), apresentando a educação bilíngue como desejo e luta da comunidade surda. Uma década depois, diversos caminhos foram traçados, alguns inclusive em colaboração com o Ministério da Educação. Em 2012, no momento em que se discutem planos para os próximos dez anos da educação do Brasil, os surdos mais graduados em nosso país - doutores surdos -, formados nos meandros da educação brasileira, produziram a Carta aberta ao Ministro da Educação" (2012), apontando para tensões no atendimento educacional da surdez, defendendo a educação bilíngue e indicando a SME/SP como um serviço público de educação que respeita a diversidade dos surdos e favorece uma escola democrática ao manter dois tipos de serviços: o da escola bilíngue para surdos e o da escola inclusiva bilíngue.

\section{Consideraçōes finais}

A atual política nacional de inclusão escolar tem recebido severas críticas por não aprofundar as ações relativas às especificidades de seu alunado-alvo, dissolvendo a diferença na igualdade abstrata de indivíduos em salas regulares. Ela defende uma inclusão incondicional (SÁ, 2011). Contudo, iniciativas como as aqui indicadas pela legislação analisada apontam para uma reflexão no interior de uma Secretaria Municipal de Educação que busca desenhar um espaço educacional sensível às necessidades pedagógicas dos sujeitos surdos. A análise da legislação indica a previsão de figuras profissionais novas e necessárias à educação de surdos; a intenção de promover formação continuada para seus quadros, de modo a ampliar as possibilidades de um atendimento de qualidade aos alunos surdos; e o intento assumir compromisso com uma perspectiva educacional bilíngue, seja na escola de surdos, seja no espaço inclusivo.

0 conhecimento construído no percurso do atendimento a alunos surdos no município de São Paulo revela-se favorecedor de uma reflexão sobre a trajetória da educação de surdos, ampliando a proposta de atendimento tanto às escolas de surdos, quanto às escolas organizadas na perspectiva da educação inclusiva bilíngue. Os documentos analisados indicam a escolha de uma educação plural, entendendo que pessoas com surdez têm diversas necessidades e condições, e que a inclusão social desses sujeitos, no que tange à educação, pode dar-se com diferentes roupagens. Conhecer melhor essa proposta pode orientar novas políticas públicas atentas à condição bilíngue implicada na surdez. Cabe, então, acompanhar os efeitos da implementação de tal legislação a fim de compreender seus impactos sobre as práticas educacionais que envolvem alunos surdos.

\section{Referências}

BAKHTIN, Mikhail (Volochínov). Marxismo e filosofia da linguagem. Trad. Michel Lahud e Yara Frateschi Vieira. São Paulo: Hucitec, 1986.

BAKHTIN, Mikhail. Estética da criação verbal. São Paulo: Martins Fontes, 1997.

BRASIL. Lei n 10.436, de 24 de abril de 2002. Dispõe sobre a Língua Brasileira de Sinais - Libras e dá outras providências. Diário Oficial da União, Brasília, 25 abr. 2002. Disponível em: <http://www.planalto.gov.br/ccivil_03/Leis/2002/L10436.htm>. Acesso em: 22 mai. 2007. 
Decreto-Lei n ${ }^{0}$ 5.626, de 22 de dezembro de 2005. Regulamenta a Lei $n^{0}$ 10.436, de 24 de abril de 2002, que dispõe sobre a Língua Brasileira de Sinais - Libras, e 0 art. 18 da Lei n. 10.098, de 19 de dez. 2000. Diário Oficial da União, Brasília, 23 dez. 2005. Disponível em: <http://www.planalto.gov.br/ccivil_03/_Ato2004-2006/2005/Decreto/D5626.htm>.Acesso em: 22 mai. 2007.

CARTA aberta ao Ministro da Educação (elaborada pelos sete primeiros doutores surdos brasileiros, que atuam nas áreas de educação e linguística). 8 jun. 2012. Disponível em: <http://marianahora.blogspot.com.br/2012/06/carta-aberta-dos-doutoressurdos.html>. Acesso em: 10 jun. 2012.

CURY, Carlos Roberto Jamil. Direito à educação: direito à igualdade, direito à diferença. Cadernos de Pesquisa, Campinas, n. 116, p. 245-262, jul. 2002.

FENEIS (Federação Nacional de Educação e Integração dos Surdos). A educação que nós surdos queremos. Documento elaborado no Pré-Congresso ao V Congresso Latino Americano de Educação Bilíngue para Surdos. Porto Alegre: UFRGS, 1999.

FERNANDES, Sueli. Práticas de letramento na educação bilíngue para surdos. Curitiba: SEED, 2006.

Educação de surdos. Curitiba: Editora IBPEX, 2012. (Série Inclusão Escolar).

FRANCO, Monique. Educação superior bilíngue para surdos: o sentido da política inclusiva como espaço da liberdade: primeiras aproximações. Revista Brasileira de Educação Especial, Marília, v. 15, n. 1, p. 15-30, jan./abr. 2009.

GESSER, Audrei. LIBRAS: que língua é essa? Crenças e preconceitos em torno da língua de sinais e da realidade surda. São Paulo: Parábola Editorial, 2009.

INES (Instituto Nacional de Educação de Surdos). Curso bilíngue de pedagogia do INES. 2012. Disponível em: <http://www.ines. gov.br/Lists/Atendimentos/DispForm.aspx?ID=7>. Acesso em: 23 mai. 2011.

LACERDA, Cristina Broglia Feitosa de. A inserção da criança surda em classe de crianças ouvintes: focalizando a organização do trabalho pedagógico. In: REUNIÃO ANUAL DA ANPED, 23., 2000, Caxambú. Anais... Rio de Janeiro: ANPED, 2000a. Disponível em: <www.anped.org.br/23/textos/1518t.pdf>. Acesso em: 20 dez. 2012.

0 intérprete de língua de sinais no contexto de uma sala de aula de alunos ouvintes: problematizando a questão. In: LACERDA, Cristina Broglia Feitosa de; GÓES, Maria Cecília Rafael de (Orgs.). Surdez: processos educativos e subjetividade. São Paulo: Lovise, 2000b. p. 51-84.

0 intérprete educacional de língua de sinais no ensino fundamental: refletindo sobre limites e possibilidades In: LODI, Ana Claudia Balieiro et al. Letramento e minorias. Porto Alegre: Mediação, 2002. p. 120-128.

0 que dizem/sentem alunos participantes de uma experiência de inclusão escolar com aluno surdo. Revista Brasileira de Educação Especial, Marília, v. 13, p. 257-280, 2007.

Intérprete de Libras em atuação na educação infantil e no ensino fundamental. Porto Alegre: Editora Mediação, 2009.

LEBEDEFF, Tatiana Bolivar. A educação dos surdos na região do planalto médio rio-grandense: uma problematização das condições lingüísticas e de escolarização. In: REUNIÃO ANUAL DA ANPED, 33., 2010, Caxambú. Anais... Rio de Janeiro: ANPED, 2010.

LODI, Ana Claudia Balieiro. A leitura como espaço discursivo de construção de sentidos: oficinas com surdos. Tese (Doutorado em Linguística Aplicada e Estudos da Linguagem) - Pontifícia Universidade Católica de São Paulo, São Paulo, 2004.

Plurilinguismo e surdez: uma leitura bakhtiniana da história da educação dos surdos. Educação e Pesquisa, São Paulo, v. 31, n. 3, p. 409-424, set./dez. 2005.

LODI, Ana Claudia Balieiro; LACERDA, Cristina Broglia Feitosa. A inclusão escolar bilíngue de alunos surdos no ensino infantil e fundamental: princípios, breve histórico e perspectivas. In: Uma escola duas línguas: letramento em língua portuguesa e língua de sinais nas etapas iniciais de escolarização. Porto Alegre: Editora Mediação, 2009. p. 7-32.

MEGALE, Antonieta Heyden. Bilinguismo e educação bilíngue: discutindo conceitos. ReVEL, v. 3, n. 5, ago. 2005. 
MELETTI, Silvia Márcia Ferreira; BUENO, José Geraldo Silveira. Escolarização de alunos com deficiência: uma análise dos indicadores sociais no Brasil (1997-2006). In: REUNIÃO ANUAL DA ANPED, 33., 2010, Caxambú. Anais... Rio de Janeiro: ANPED, 2010.

MOURA, Maria Cecília de. 0 surdo: caminhos para uma nova identidade. Rio de Janeiro: Revinter, 2000.

PEREIRA, Maria Cristina Cunha. Leitura, escrita e surdez. 1. ed. São Paulo: FDE, 2005.

QUADROS, Ronice Muller de. Políticas linguísticas e educação de surdos em Santa Catarina: espaço de negociações. Cadernos CEDES, Campinas, v. 26, n. 69, p. 141-161, ago. 2006.

SÁ, Nídia Regina Limeira. Escolas e classes de surdos: opção político-pedagógica legítima. In: SÁ, Nídia Regina Limeira (Org.) Surdos: qual escola? Manaus: Editora Valer e Educa, 2011. p. 17-62.

SÃO PAULO. Decreto n 52.785, de 10 de novembro de 2011. Cria as Escolas Municipais de Educação Bilíngue para Surdos EMEBS na Rede Municipal de Ensino. Diário Oficial da Cidade de São Paulo, São Paulo, 22 nov. 2011 a.

. Portaria n ${ }^{0}$ 5.707, de 12 de dezembro de 2011. Regulamenta o Decreto 52.785 de 10/10/11 que criou as escolas de educação bilíngüe para surdos - EMEBS e dá outras providências. Diário Oficial da Cidade de São Paulo, São Paulo, 13 dez. $2011 \mathrm{~b}$.

SHIROMA, Eneida Oto; CAMPOS, Roselane Fátima; GARCIA, Rosalba Maria Garcia. Decifrar textos para compreender a política: subsídios teórico-metodológicos para análise de documentos. Perspectiva: Revista do Centro de Ciências da Educação, Florianópolis, n. 2, p. 427-446, jul./dez. 2005.

SILVA, Angélica Bronzatto de Paiva e; PEREIRA, Maria Cristina da Cunha. A imagem que professoras de escola regular têm em relação à aprendizagem do aluno surdo. Estudos de Psicologia, Campinas, v. 20, n. 2, p. 5-13, ago. 2003.

SKLIAR, Carlos A. Localização política da educação bilíngue para surdos. In: para surdos: processos e projetos pedagógicos. Porto Alegre: Mediação, 1999. p. 7-14.

(Org.). Atualidade da educação bilíngue

SVARTHOLM, Kristina. Educação bilíngue para surdos na Suécia: teoria e prática. In: MOURA, Maria Cecilia; VERGAMINI, Sabine Antinialli Arena; CAMPOS, Sandra Regina Leite (Orgs.). Educação para surdos: práticas e perspectivas. São Paulo: Editora Santos, 2008. p. 119-144.

TEIXEIRA, Lucia Helena Gonçalves. Cultura organizacional e projeto de mudança em escolas públicas. Campinas; São Paulo: Autores Associados: 2002.

VYGOTSKY, Lev Semenovich. A formação social da mente. São Paulo: Martins Fontes, 1998.

Recebido em: 22.06.2012

Aprovado em: 15.10.2012

Cristina Broglia Feitosa de Lacerda possui graduação (1984) em Fonoaudiologia pela Universidade São Paulo (USP). É mestre (1992) e doutora (1996) em Educação pela Universidade Estadual de Campinas (Unicamp) e docente na Graduação e na Pós-Graduação em Educação Especial da Universidade Federal de São Carlos (UFSCar).

Neiva de Aquino Albres possui graduação (1999) em Fonoaudiologia pela Universidade Católica Dom Bosco (UCDB), é mestre (2005) em Educação pela Universidade Federal de Mato Grosso do Sul (UFMS) e doutoranda em Educação Especial pela Universidade Federal de São Carlos (UFSCar).

Silvana Lucena dos Santos Drago é pedagoga com especialização em Distúrbios da Áudio-Comunicação, Administração e Supervisão Escolar pela Pontifícia Universidade Católica de São Paulo (PUC/SP) e assessora técnica responsável pela Diretoria de Orientação Técnica em Educação Especial da Secretaria Municipal de Educação de São Paulo. 